\title{
CARACTERIZACIÓN ANATÓMICA DE HOJA DE RECURSOS GENÉTICOS DE Hymenachne amplexicaulis (RUDGE) NEES
}

\author{
LEAF ANATOMICAL CHARACTERIZATION OF Hymenachne \\ amplexicaulis (RUDGE) NEES GENETIC RESOURCES
}

\author{
Alfredo Arellano-Cueto' ${ }^{1}$ Adrián R. Quero-Carrillo'*, Hilda A. Zavaleta-Mancera', \\ Manuel Silva-Luna², Mario A. Cobos-Peralta' y Paulino Pérez-Rodríguez ${ }^{1}$
}

\begin{abstract}
'Campus Montecillo, Colegio de Postgraduados. Km. 36.5 carr. México-Texcoco. 56230, Montecillo, Texcoco, Edo. de Méx. ${ }^{2}$ Costa de Jalisco, Instituto Nacional de Investigaciones Forestales, Agrícolas y Pecuarias. Km. 204 carr. Guadalajara-Barra de Navidad. 48850, La Huerta, Jal.

*Autor para correspondencia (queroadrian@colpos.mx)
\end{abstract}

\section{RESUMEN}

La anatomía foliar de 32 ecotipos de pasto Azuche, Hymenachne amplexicaulis (Rudge) Nees, nativos de México fue comparada con el objetivo de identificar atributos forrajeros valiosos dentro de la diversidad genética. El material vegetal fue obtenido de una colección de pastos establecida y evaluada por el Colegio de Postgraduados en el Campo Experimental del Instituto Nacional de Investigaciones Forestales, Agrícolas y Pecuarias (INIFAP) en La Huerta, Jalisco. El porcentaje y variabilidad de los tejidos foliares se midieron mediante análisis histológico y segmentación de imágenes en cortes transversales de hoja: epidermis, células buliformes, mesofilo, aerénquima, esclerénquima, vaina del haz vascular, floema y xilema a los 28 días después del rebrote. Los datos se analizaron mediante métodos multivariados y análisis de varianza. No hubo variación intra-específica $(P \leq$ $0.05)$ entre ecotipos; sin embargo, se observaron diferencias $(P \leq 0.05)$ entre grupos formados con base en los tejidos foliares: 1) altamente digestibles, 2) medianamente digestibles y 3) no digestibles. Los análisis de laboratorio permitieron identificar ecotipos con calidad forrajera. Se identificaron ecotipos con una proporción alta de tejidos digestibles (mesófilo y aerénquima), lo cual puede ser importante para la selección genética. La variabilidad genética de Azuche se encuentra asequible para evaluación, y la especie posee alto potencial productivo bajo condiciones de riego en ambientes tropicales, lo cual requiere documentarse a mayor detalle.

Palabras clave: Hymenachne amplexicaulis, Azuche, caracterización estructural, porcentaje de tejidos, diversidad genética.

\section{SUMMARY}

The leaf anatomy of 32 ecotypes of Azuche, Hymenachne amplexicaulis (Rudge) Nees pasture grass native to México was compared to identify valuable forage attributes within the native genetic diversity. Plant material was obtained from a pasture collection established and evaluated by the Colegio de Postgraduados at La Huerta, Jalisco experimental station of Instituto Nacional de Investigaciones Forestales, Agrícolas y Pecuarias (INIFAP). The percentage and variability of foliar tissues (epidermis, bulliform cells, mesophyll, aerenchyma, sclerenchyma, vascular bundle sheath, phloem, and xylem) were measured through histological analysis and image segmentation on cross foliar sections 28 days after regrowth. Data were analyzed using multivariate methods and analysis of variance. There was no intraspecific variation $(P \leq 0.05)$ among ecotypes; however differences $(P \leq 0.05)$ were observed among groups formed based on foliar tissues: 1) highly digestible, 2) medium digestible and 3) non-digestible. Laboratory analyses allowed the identification of forage quality ecotypes. Ecotypes with high digestible tissue proportion (mesophyll and aerenchyma) were identified, which may be important for genetic selection. Genetic variability of Azuche is available for evaluation, and the species possesses high productive potential under irrigation in tropical environments, which needs to be documented in detail.

Index words: Hymenachne amplexicaulis, Azuche, structural characterization, tissue percentage, genetic diversity.

\section{INTRODUCCIÓN}

Las gramíneas (Poaceae) nativas constituyen un recurso genético valioso para el pastoreo y producción de forraje en muchas partes del mundo; lo anterior, debido al hecho de que se desarrollan en condiciones marginales y restrictivas para muchos otros cultivos, no aptas para la producción intensiva. El potencial forrajero de estas especies está asociado con características anatómicas que les permiten adaptarse a condiciones ambientales diversas (Quero et al., 2007). Entre las gramíneas, existen diferentes mecanismos de asimilación de $\mathrm{CO}_{2}$, lo cual está asociado con el potencial de aprovechamiento de la humedad disponible.

Así, las gramíneas con ruta fotosintética $\mathrm{C}_{4}$ dominan el trópico; lo anterior, debido a que están adaptadas a elevada irradiación, temperatura y toleran sequía, con rendimientos de materia seca superiores a aquellos observados en gramíneas $\mathrm{C}_{3}$; sin embargo, la calidad forrajera de las gramíneas $\mathrm{C}_{4}$ es inferior, especialmente después del inicio de la senescencia foliar. Las hojas de especies $\mathrm{C}_{3}$ y $\mathrm{C}_{4}$ tienen diferencias anatómicas y bioquímicas que determinan la calidad del forraje y su degradación durante la digestión del mismo, lo que se relaciona directamente con la productividad animal (Heinzen et al., 2002). Se sabe que con la misma cantidad de materia seca puede obtenerse mayor productividad del ganado con gramíneas $\mathrm{C}_{3}$ templadas, en comparación con gramíneas tropicales $\mathrm{C}_{4^{\prime}}$ debido a la mayor calidad forrajera 
natural de las especies $\mathrm{C}_{3}$.

Las especies con vía fotosintética $\mathrm{C}_{3}$ tienen menor proporción de tejidos lignificados en comparación con las especies C $_{4}$ (Akin y Burdick, 1975), esta diferencia fue señalada como una variable que afecta la digestibilidad del forraje, principalmente durante la maduración y senescencia (Gasser et al., 2002). Se han desarrollado estudios sobre anatomía vegetal y tipo de tejidos que pueden ser digeridos de acuerdo con su cantidad de fibras y composición (Akin y Burdick, 1975) y se ha indicado que el esclerénquima y el tejido vascular se digieren muy lentamente, ya que contienen lignina, un compuesto que hace a los tejidos no degradables, y especialmente durante la senescencia la proporción de estos tejidos aumenta (Buxton y Redfearn, 1997).

Las láminas foliares de gramíneas $\mathrm{C}_{3}$ presentan mayor digestibilidad de tejidos en comparación con aquellos de especies $\mathrm{C}_{4^{\prime}}$ porque las primeras tienen mayor número de células del mesófilo. Las células del mesófilo, floema, epidermis, parénquima y vaina del haz vascular de las especies $\mathrm{C}_{3}$ se degradan totalmente en el rumiante, en contraste con las especies $\mathrm{C}_{4^{\prime}}$ donde éstas se degradan de manera lenta o parcial (Guevara y Ramia, 2007). Estas diferencias en degradabilidad se deben a que en especies $\mathrm{C}_{4}$ las hojas contienen mayor cantidad de fibras y tejidos lignificados que en las especies $C_{3}$ (Akin y Burdick, 1975).

En zonas tropicales, especies nativas como Azuche [Hymenachne amplexicaulis (Rudge) Nees] son de importancia forrajera, se desarrollan en áreas de bajíos que se inundan de forma estacional o semipermanentemente. En áreas bajas o cuencas endorreicas ocurre una retención mayor de humedad por periodos amplios, debido a una permeabilidad baja del suelo o por su topografía (Enríquez et al., 2015). Estas zonas pueden durar anegadas y secarse únicamente en años con sequías extremas. En estas áreas, la inundación puede ser una condición cíclica o perenne, mientras que en otras se considera un evento raro, ya sea debido a tormentas severas, mal drenaje o desborde de ríos y canales en respuesta a eventos climáticos recurrentes de intensidad variable (Enríquez, 2005 Com. Pers. ${ }^{1}$ ).

Las especies que crecen en estas zonas están sujetas a condiciones extremas que alternan el exceso y la escasez de humedad. Una estrategia de supervivencia es evadir la sequía mediante la producción de semilla para la siguiente temporada de lluvias; así, los forrajes desarrollan estrategias adaptativas como cambios anatómicos, morfológicos

'Enríquez-Quiroz J. F. (2005) Recolección y evaluación de germoplasma de Azuche Hymenachne amplexicaulis (Rudge) Nees, gramínea forrajera de tierras inundables del trópico mexicano. Tesis de Doctorado. Colegio de Postgraduados. Montecillo, Edo. de México, México $147 \mathrm{p}$. y fisiológicos que mejoran el intercambio de gases, lo que mantiene la producción energética para tolerar sequías extremas (Grimoldi et al., 2005; Striker, 2012). La formación de aerénquima y raíces adventicias son cambios anatómicos relevantes, porque facilitan el transporte de oxígeno desde los órganos aéreos hacia los tejidos sumergidos, lo que permite su supervivencia y desarrollo (Colmer, 2003; Fabbri et al., 2005; Grimoldi et al., 2005).

Azuche es una especie nativa con atributos que facilitan su persistencia en áreas inundables, con ruta fotosintética típica $\mathrm{C}_{3^{\prime}}$ lo que permite su establecimiento en bajíos inundables del trópico mexicano, bajo condiciones alternas de inundación-sequía pero no se conoce su potencial productivo fuera de su área natural de distribución, bajo riego y pastoreo intensivo. La mayor parte de información sobre el pasto Azuche incluye una descripción general botánica y morfológica del pasto, pero no se conoce el potencial de la diversidad natural y mucho menos, la variabilidad en los componentes morfo-anatómicos de la lámina foliar, con un enfoque ganadero. Se han investigado características estructurales de anatomía en hoja para explicar su adaptación a ambientes marginales inundables, porque estos cambios son de gran importancia en las plantas para soportar el estrés ambiental y subsistir (Child et al., 2003; Equiza y Tognetti, 2002).

Para cualquier especie vegetal, en su centro de origen existe amplia variabilidad intra-específica y ecotipos localmente adaptados a condiciones regionales específicas en las que se han desarrollado por milenios sin influencia antropogénica (Begon et al., 2006). El centro de origen de Azuche es América tropical y, por lo tanto, su diversidad genética se encuentra asequible para selección y mejoramiento. El objetivo del presente estudio fue comparar la variabilidad anatómica de la lámina foliar, mediante la evaluación del porcentaje de componentes de hoja, en recursos genéticos recolectados en diferentes regiones del trópico mexicano.

\section{MATERIALES Y MÉTODOS}

\section{Localización}

Los tejidos de hoja se obtuvieron de una muestra ex situ de recursos genéticos de pasto Azuche (Hymenachne amplexicaulis), ensamblada por el Colegio de Postgraduados en conjunto con el Instituto Nacional de Investigaciones Forestales, Agrícolas y Pecuarias (INIFAP); la cual, se encuentra establecida en el Campo Experimental Costa de Jalisco, del INIFAP, en La Huerta, Jalisco (19 31' 15" N, 104 32' 00" O, 198 msnm). El clima es Aw , con lluvias en verano, precipitación promedio anual de $1452 \mathrm{~mm}$ y temperatura media anual de $25^{\circ} \mathrm{C}$ (Vizcaíno et al., 2005). 


\section{Obtención del material vegetal}

Después de una estimación exploratoria de rendimiento de materia seca de forraje y a partir de una colección de 64 ecotipos recolectados en diversas regiones del trópico húmedo y seco de México (Vega, 2015, Com. Pers. ${ }^{2}$ ), se seleccionaron los 32 ecotipos de mayor potencial de producción de materia seca para este estudio; posteriormente, se realizó corte de uniformidad para iniciar el muestreo de hoja, a la misma edad de rebrote.

\section{Anatomía}

Se muestrearon láminas foliares cuando éstas alcanzaron 95 \% de interceptación luminosa (IL). En época de Iluvias, se recolectaron cinco hojas completamente expandidas con lígula expuesta y sin senescencia. De cada hoja se obtuvieron fragmentos (de 3 a $4 \mathrm{~cm}$ ) de la parte central de lámina, los cuales se fijaron con una solución FAA (10\% formaldehído, $5 \%$ ácido acético, $52 \%$ etanol y $33 \%$ agua) durante $72 \mathrm{~h}$. El material vegetal fijado en FAA se enjuagó con agua corriente y se colocó en solución GAA ( $25 \%$ glicerol $+50 \%$ etanol $+25 \%$ agua), hasta su procesamiento. Los tejidos se cortaron transversalmente con micrótomo de mano (Jung-microtome) de $50 \mu \mathrm{m}$ de grosor; los cuales, se transfirieron a solución $50 \%$ de etanol. La presencia de lignina se identificó con floroglucinol (2\% en etanol) y $\mathrm{HCl}$ (50 \%) (Ruzin, 1999). La medición y agrupación de componentes estructurales de alta, media y baja digestibilidad de la lámina foliar se realizó en el Laboratorio de Anatomía e Histoquímica Vegetal del Colegio de Postgraduados.

\section{Medición de tejidos}

Los cortes se observaron con microscopio óptico compuesto (Leica DM4, Wetzlar, Alemania) y se fotografió la parte central, lateral y marginal de la hoja con cámara digital (Cyber Shot, 4M Sony). En las hojas se identificó floema, mesófilo, aerénquima, vaina del haz vascular y su extensión, células buliformes, epidermis y el tejido lignificado de xilema y esclerénquima. Las imágenes se segmentaron con el programa GIMP versión 2.8.8 (https://www.gimp. org). El área $\left(\mu \mathrm{m}^{2}\right)$ de estos tejidos se midió y posteriormente se expresó en porcentaje (\%) como el área ocupada en relación con el tejido total. Las mediciones se realizaron con la ayuda del software Image Tools, para Windows (versión 3.00, University of Texas Health Science Center, San Antonio, TX, USA).

${ }^{2}$ Vega L. M. A. (2015) Dinámica de crecimiento y calidad nutritiva de recursos genéticos de Hymenachne amplexicaulis (Rudge) Nees. Tesis Maestría en Ciencias. Colegio de Postgraduados. Montecillo, Estado de México. 72 p.

\section{Diseño experimental y análisis estadístico}

El diseño experimental fue completamente al azar en el que se analizaron tres hojas por ecotipo. Las medias fueron comparadas con la prueba de Tukey $(P \leq 0.05)$. Se realizó agrupamiento de genotipos con base en el porcentaje de la digestibilidad de sus tejidos; para ésto, se utilizaron métodos jerárquicos, basados en la matriz de distancias Euclidianas y, como medida de proximidad entre grupos, el criterio de vecino más lejano (encadenamiento completo). Los análisis fueron realizados en el paquete estadístico $R$ (R Core Team, 2016).

\section{RESULTADOS Y DISCUSIÓN}

Azuche es una especie estolonífera, con tallos que se extienden sobre el suelo húmedo o flotan sobre la superficie del agua, a partir de cuyos nudos se producen raíces y hojas de nuevos brotes. Estas características le confieren gran plasticidad morfológica, como a otras especies que crecen en condiciones similares (Fabbri et al., 2005). Este pasto puede desarrollar entrenudos largos en inundaciones de profundidad elevada o entrenudos cortos en profundidades someras; lo anterior resulta en producción de raíces en cada nudo; las cuales promueven crecimiento cespitoso conforme se reduce el nivel de agua y, por tanto follaje cerrado al reducirse la humedad, que reduce las pérdidas hídricas por evaporación en hojas, cuando los niveles de inundación se reducen hasta la estación de estiaje.

Entre los 32 ecotipos analizados en este estudio, no se encontraron diferencias morfológicas significativas $(P \leq$ 0.05) con relación al arreglo de los tejidos que presenta la hoja de pasto Azuche. La epidermis adaxial está formada por un grupo de células monoestratificadas, cortas y redondeadas; la epidermis abaxial, también tiene un solo estrato de células parenquimáticas, cortas y papilosas pero interrumpida por grandes células buliformes en grupos de seis a ocho (Figura 1A), las cuales tienen paredes anticlinales delgadas que participan en movimientos de plegamiento e involución de la hoja durante su desarrollo y en su fase adulta, en función de la humedad (Alonso, 2011). Estas células se encuentran distribuidas en toda la epidermis a partir del segundo haz vascular de tercer orden y están ausentes cerca de la nervadura central (Figura 2A). La extensión de la vaina de los haces forma fibras subepidérmicas en la cara abaxial y adaxial.

Los haces vasculares (HV) se denominaron de acuerdo con su tamaño, como primer orden (mayores), segundo orden (medianos) y tercer orden pequeños (Figuras 1A y 2A). Los HV de primer y tercer orden presentan extensión de la 


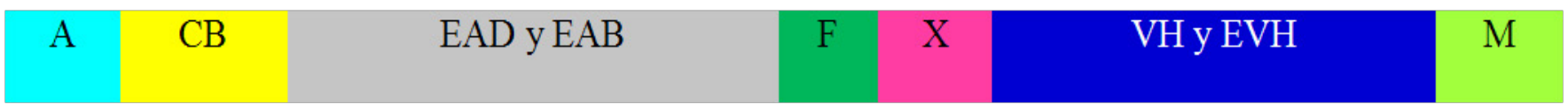

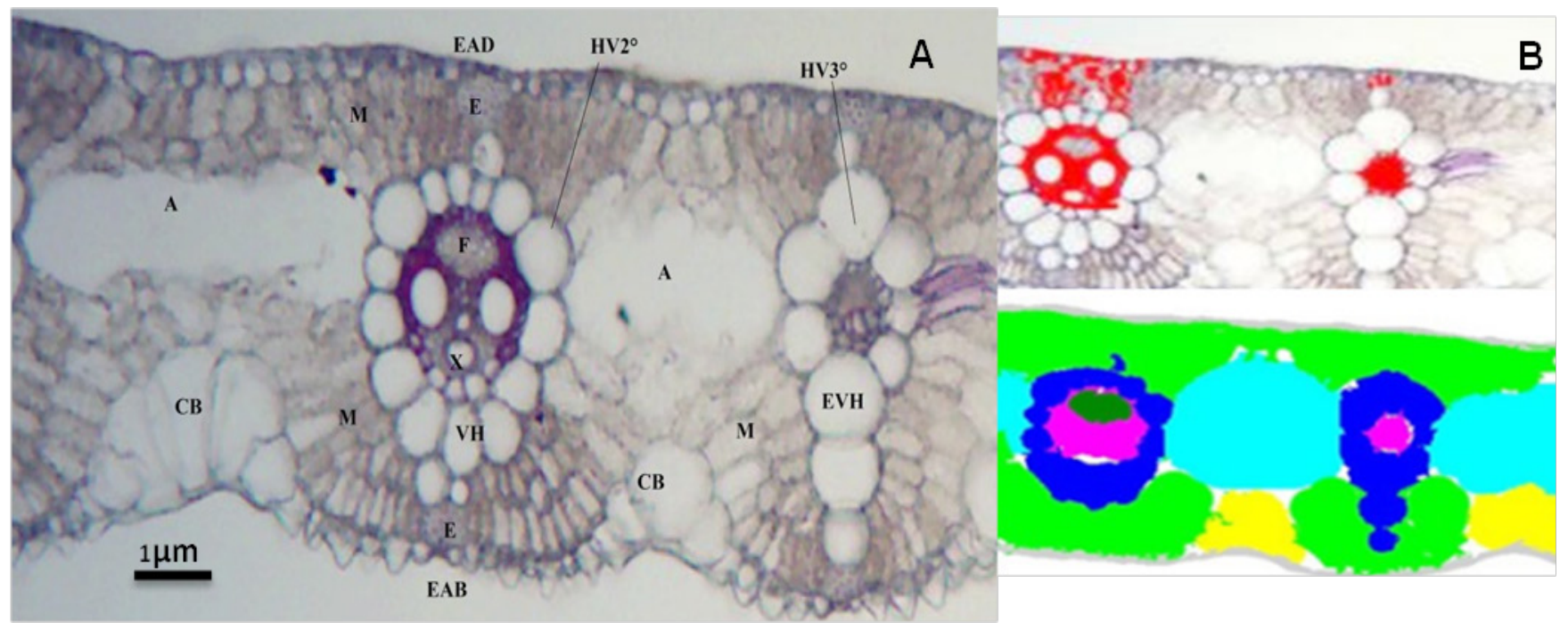

Figura 1. Corte transversal en la región marginal de la lámina de Hymenachne amplexicaulis. A) Corte transversal 15 $\mu \mathrm{m}$ con haces vasculares secundarios $\left(\mathrm{HV} 2^{\circ}\right)$ y terciarios $\left(\mathrm{HV} 3^{\circ}\right)$. B) Agregación de lignina en rojo; C) Segmentación de tejidos componentes de la hoja mediante el software GIMP 2.8. (A), aerénquima; (CB), células buliformes; (EAD), epidermis adaxial; $(E A B)$, epidermis abaxial; $(E)$, esclerénquima; $(F)$, floema; $(X)$, xilema; $(V H)$, vaina del haz vascular; $(\mathrm{EVH})$, extensión de la vaina del haz; $\left(\mathrm{HV} 2^{\circ}\right)$, haz vascular de $2^{\circ}$ orden; $\left(H V 3^{\circ}\right)$, haz vascular de $3^{\circ}$ orden; $(\mathrm{M})$, mesófilo.
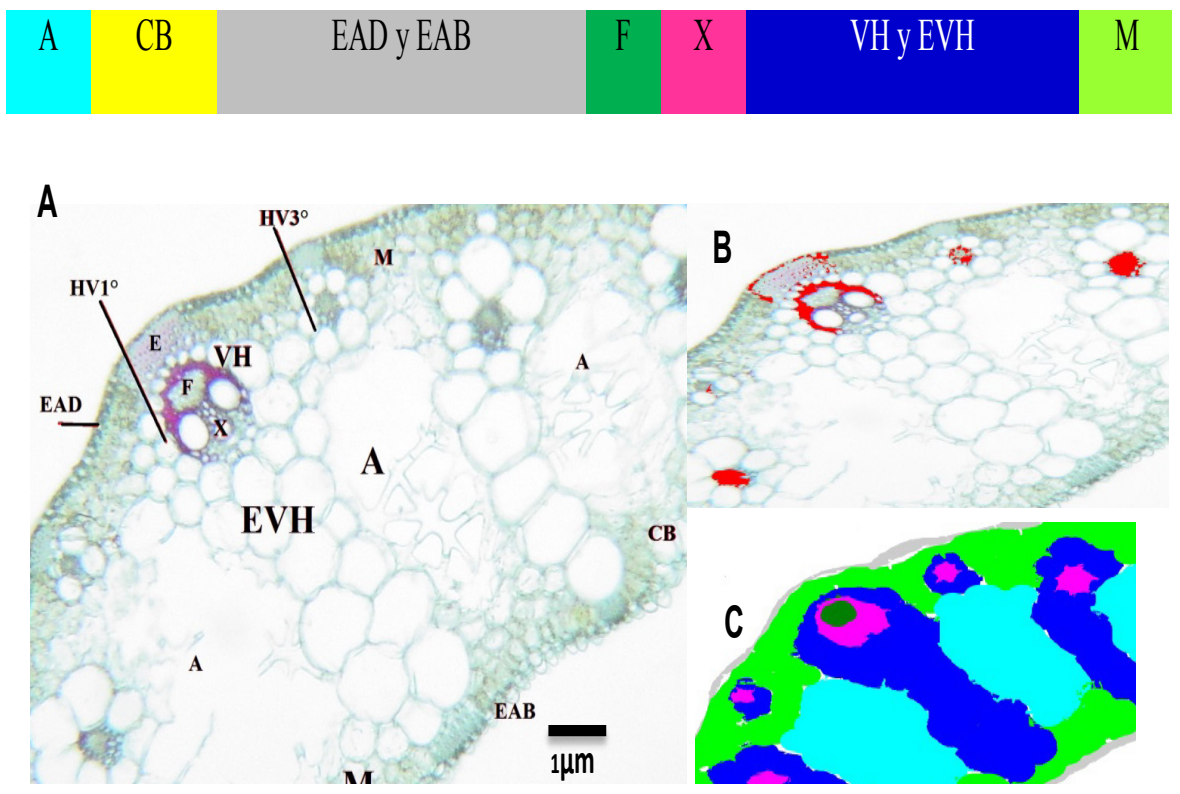

Figura 2. Corte transversal de la región central de la lámina de Hymenachne amplexicaulis. Nervadura central o primaria y estructura anatómica de la parte central de la lámina foliar de A) Corte transversal $15 \mu \mathrm{m}$. B) Presencia de lignina en hoja en rojo. C) Fragmentación de la imagen en los tejidos componentes de hoja mediante GIMP 2.8.8. (A), aerénquima; (CB), células buliformes; $(E A D)$, epidermis adaxial; $(E A B)$, epidermis abaxial; $(E)$, esclerénquima; $(F)$, floema; $(X)$, xilema; $(V H)$, vaina del haz vascular; $(\mathrm{EVH})$, extensión de la vaina del haz; $\left(\mathrm{HV}^{\circ}{ }^{\circ}\right)$, haz vascular de 1er orden; $\left(\mathrm{HV}^{\circ}\right)$, haz vascular de 3er orden; (M), mesófilo. 
vaina del haz, un grupo de células que se extienden desde el haz vascular hacia la cara abaxial de la hoja (Figura 2A). Las paredes externas de la epidermis son gruesas. Las características anatómicas de la hoja son de interés porque éstas ayudan a reducir eficientemente la pérdida de humedad por evaporación (Csurhes et al., 1999; Medina y Motta, 1990). En gramíneas no hay diferenciación entre parénquima en empalizada y esponjoso (Alonso, 2011), como en el caso del mesófilo en Azuche (Figura 1). Azuche presenta aerénquima que permite la circulación de aire $\left(\mathrm{O}_{2}\right.$ y CO aun cuando se encuentra sumergida (Colmer y Voesenek, 2009).

En algunos ecotipos con lámina ancha el HV de segundo orden tiene extensión de la vaina del haz lignificada. El número de HV en la lámina varía de acuerdo con el tamaño de la hoja, pero se encontró relación de tres HV de tercer orden después del HV de primer orden, seguido por un HV de segundo orden. Algunos ecotipos presentaron hasta seis HV de tercer orden entre los haces vasculares de segundo orden. Con respecto a especies $\mathrm{C}_{3^{\prime}}$ la cantidad de HV no tiene efecto sobre la digestibilidad $(P \leq 0.05)$ porque éstos presentan paredes delgadas que facilitan la degradación, en comparación con especies $\mathrm{C}_{4^{\prime}}$ las cuales, debido a las paredes tangenciales internas, se suberizan o lignifican lo que genera una barrera y evita posteriormente la degradación de los HV (Bianco et al., 2004).

Los HV presentan un arreglo colateral, con floema de orientación adaxial y xilema de orientación abaxial, con protoxilema y metaxilema conspicuos (Figuras 1A y 2A). La vaina del HV ha sido objeto de diversos estudios debido a sus funciones esenciales como fotosíntesis e intercambio de sustancias entre el mesofilo y los tejidos del sistema vascular (Zheng et al., 2002) y también por su importancia en la nutrición de rumiantes, a causa de su influencia en la extensión de la superficie de adhesión de microorganismos del rumen o sus enzimas al tejido digestible.

El diagrama de caja y bigotes para el porcentaje de cada tejido componente en las hojas para los 32 ecotipos (Figuras $3 \mathrm{~A}$ y $3 \mathrm{~B}$ ) muestra el porcentaje de tejidos altamente digestibles, medianamente digestibles y no digestibles. No se observaron diferencias significativas $(P \leq 0.05)$ entre ecotipos con respecto al porcentaje de área de cada tejido componente; por lo tanto, se realizó un agrupamiento jerárquico de los ecotipos con base en los porcentajes de tejidos altamente digestibles, medianamente digestibles y no digestibles (Akin y Burdick, 1975). Se obtuvieron seis grupos bien definidos (Figura 4) a los que se les realizó análisis de varianza entre ellos, y se encontraron diferencias significativas $(P \leq 0.05)$. El mesófilo y el aerénquima son los tejidos de mayor área en Azuche, 36 y $23 \%$, respectivamente, en los que se encontraron los valores más altos en el grupo 6 (Figura 5). El mesófilo es esencial en la anatomía foliar, porque permite la difusión de $\mathrm{CO}_{2}$ y es el principal tejido fotosintético, además de tener paredes celulares delgadas, de alta digestibilidad y contenido celular relativamente alto, este último es más elevado en hojas jóvenes (Agnusdei, 2007; Akin y Burdick, 1975).

En esta especie el porcentaje de tejido lignificado (xilema + esclerénquima) fue de $4.7 \%$, lo que indica que es altamente digestible. Los ecotipos 1, 6, 7, 24 y 27, del grupo seis mostraron el menor porcentaje de tejido lignificado, $4.5 \%$, lo cual está relacionado con el porcentaje de tejidos altamente digestibles (mesófilo y aerénquima; Figura 4).

Van Soest (1993) menciona que el efecto de la lignina se ejerce a través de su influencia sobre la accesibilidad de las bacterias y sus enzimas al tejido digestible porque el contenido celular se considera $100 \%$ digestible. Lo anterior resulta en el hecho de que la lignina es un factor importante para la degradabilidad máxima del alimento, lo que protege al contenido celular de la fermentación microbiana. Esta protección se da por: 1) La influencia sobre la superficie de adhesión para las enzimas microbianas o para los propios microorganismos con el forraje, al promoverse mayor tamaño (menor cantidad de partículas-menor superficie de adhesión) o menor tamaño (mayor cantidad de partículas - mayor superficie de adhesión) de partículas de lámina foliar en rumen y 2) Por la influencia de la accesibilidad de los tejidos digestibles al mantener o no herméticamente cerrados algunos tejidos como el floema, debido al grado de compactación de las fibras lignificadas, lo que reduce la digestibilidad total del forraje.

Como resultado de este análisis, los ecotipos del grupo seis presentan el mayor porcentaje (59\%) de tejidos altamente digestibles en hoja (mesofilo, aerénquima y floema) con respecto al resto de ecotipos analizados en este estudio y $4.5 \%$ de tejido no digestible (tejido lignificado). Aunque la epidermis de Azuche es ligeramente gruesa, y constituye el $8 \%$ de la hoja en el grupo uno, no constituye una barrera para la degradabilidad de los tejidos internos y permite la íntima adhesión de las principales especies de bacterias celulolíticas.

El mesofilo y aerénquima en este pasto se encuentran accesibles para los microorganismos y sus enzimas, se fraccionan fácilmente debido a la presencia de abundantes espacios intercelulares, lo que favorece la fragmentación del tejido; además, por el aumento en la superficie para la adhesión de microorganismos ruminales, lo que promueve una mayor acción enzimática. 

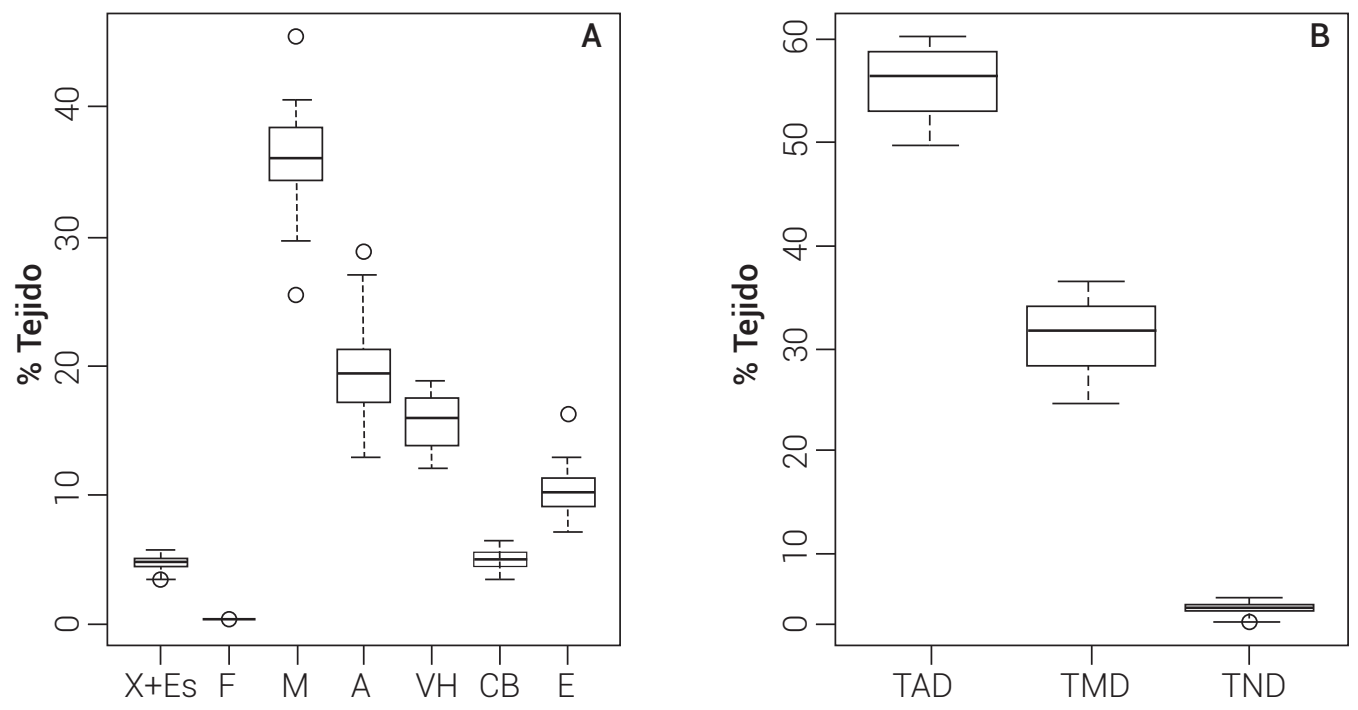

Figura 3. Componentes estructurales de la hoja de Hymenachne amplexicaulis. A) Área relativa (porcentaje) de los tejidos de la hoja. B) Área relativa de los tejidos agrupados en función de su degradabilidad. X+Es: Xilema y esclerénquima; $\mathrm{F}$ : floema; M: mesófilo; A: aerénquima; VH: vaina del haz; CB: células buliformes; E: epidermis; TAD: tejido altamente digestible; TMD: tejido medianamente digestible y TND: tejido no digestible.

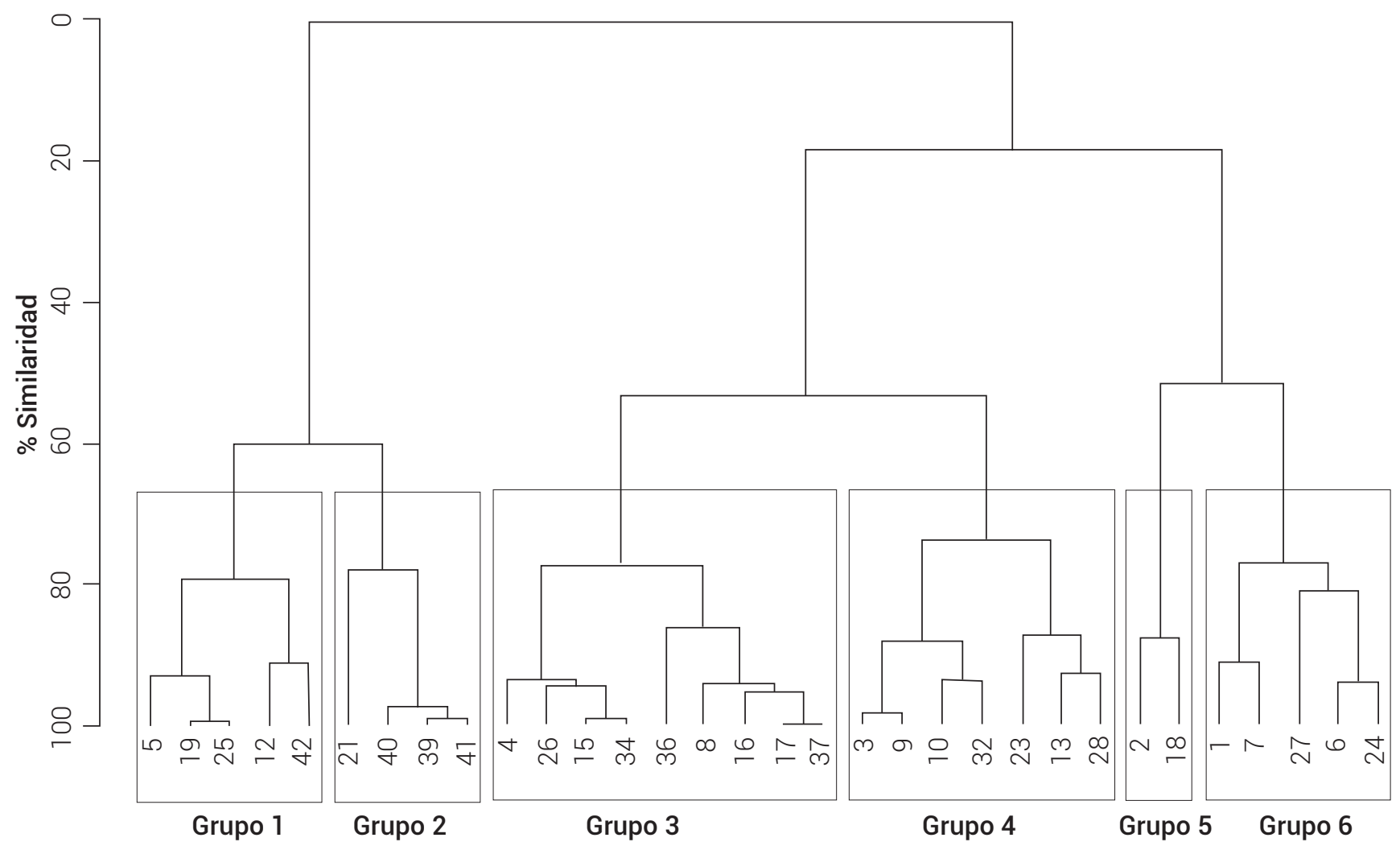

Figura 4. Agrupamiento de recursos genéticos de Hymenachne amplexicaulis, analizados con base en porcentaje de tejido con diferente digestibilidad de la hoja: tejido altamente digestible (mesófilo, aerénquima y floema); medianamente digestible (epidermis, vaina del haz y extensión, y células buliformes); no digestible (xilema y esclerénquima). 


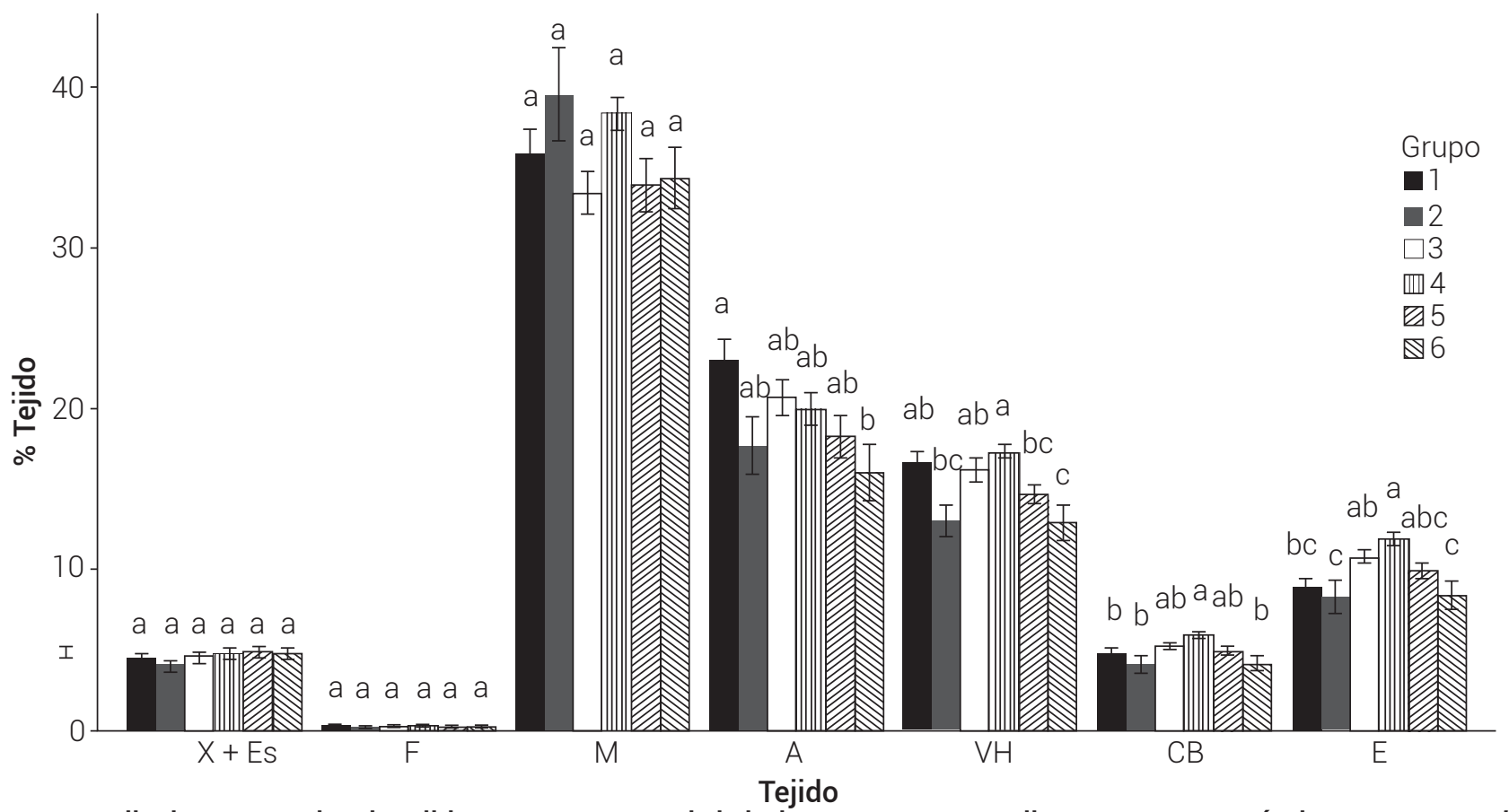

Figura 5. Media de porcentajes de tejidos componentes de la hoja y sus correspondientes errores estándar en Hymenachne amplexicaulis, por grupo. Las letras arriba de las barras indican diferencias entre grupos (Tukey; $P \leq 0.05$ ). $X+E s: X i l e m a$ y esclerénquima; F: floema; $\mathrm{M}$ : mesófilo; $\mathrm{A}$ : aerénquima; $\mathrm{VH}$ : vaina del haz vascular; $\mathrm{CB}$ : células buliformes y $\mathrm{E}$ : epidermis.

La lignina controla el grado de digestibilidad de los componentes celulares, a mayor edad del rebrote, la lignificación de las estructuras va en aumento y disminuye su degradabilidad por efecto de enzimas digestivas. Para el caso del pasto Azuche, los microorganismos tienen amplia accesibilidad a todos los tejidos componentes de la lámina foliar. Estos rasgos anatómicos le confieren una mayor digestibilidad, lo que hace a esta especie una opción de forraje de buena calidad. Los atributos señalados pueden ser la base para promover su mayor utilización bajo condiciones de riego, incrementar el potencial productivo de los predios ganaderos y definir estrategias de mejora genética en esta especie.

En otros géneros se ha reportado variabilidad foliar intraespecífica. Bernal (2015, Com. Pers.) ${ }^{3}$, en Bouteloua curtipendula, encontró variabilidad anatómica en la proporción de tejidos. Pérez y Cambi (2010), analizaron la subfamilia Chloridoideae y señalan diferencias relevantes en epidermis: costillas adaxiales y células buliformes, lo que resulta de interés taxonómico a nivel de especie, con una cantidad moderada de tejidos lignificados, lo que podría influenciar su digestibilidad. El tamaño de tejido en la estructura

${ }^{3}$ Bernal F. A. (2015) Anatomía, deposición de lignina y cultivo de tejidos en ecotipos de Bouteloua curtipendula (Michx.) Torr. Tesis de Doctorado. Colegio de Postgraduados, Montecillo, Texcoco, Edo. de Méx. $113 p$. anatómica es producto de interacciones de genotipo y ambiente, con la finalidad de mejor resiliencia de las especies ante condiciones ambientales adversas, tal es el caso de Hymenachne amplexicaulis, que soporta ciclos alternos de inundación y sequía. Esta especie, incrementa su longitud, mediante elongación de peciolos y hojas, y aumenta su superficie foliar por encima del agua, lo que permite a las plantas mantener la fotosíntesis con altas tasas de transpiración para facilitar la captura de $\mathrm{O}_{2}$ a través de las hojas.

\section{CONCLUSIONES}

Los tejidos foliares en los 32 ecotipos de Hymenachne amplexicaulis estudiados presentaron una distribución anatómica homogénea pero el área relativa (\%) de los diferentes tejidos presentó variación cuando se los ecotipos se agruparon con base en su digestibilidad.

El agrupamiento identificó dos grupos sobresalientes con mayor porcentaje de tejido altamente digestible (mesófilo, aerénquima y floema) y menor proporción de tejido lignificado.

Por su calidad potencial, similar al de especies $\mathrm{C}_{3^{\prime}}$ el pasto Azuche resulta de alto interés forrajero para regiones tropicales que se puedan habilitar con riego en la estación seca. 


\section{BIBLIOGRAFÍA}

Agnusdei M. G. (2007) Calidad nutritiva del forraje. Agromercado Temático 136:11-17.

Akin D. E. and D. Burdick (1975) Percentage of tissues types in tropical and temperate grass leaf blades and degradation of tissues by rumen microorganisms. Crop Science 15:661-668.

Alonso P. J. R. (2011) Manual de Histología Vegetal. Mundi-Prensa. Madrid, España. $326 p$

Begon M., C. R. Townsend and J. L. Harper (2006) Ecology: from Individuals to Ecosystems. 4th ed. Blackwell Publishing Ltd, Oxford, UK. $750 \mathrm{p}$.

Bianco C. A., T. A. Kraus y A. C. Vegetti (2004) La Hoja, Morfología Externa y Anatomía. Universidad Nacional de Río Cuarto. Universidad Nacional del Litoral. Argentina. $195 \mathrm{p}$.

Buxton D. R. and D. D. Redfearn (1997) Plant limitations to fiber digestion and utilization. The Journal of Nutrition 127:814S-818S.

Child R. D., J. E. Summers, J. Babij, J. W. Farrent and D. M. Bruce (2003) Increased resistance to pod shatter is associated with changes in the vascular structure in pods of a resynthesized Brassica napus line. Journal of Experimental Botany 54:1919-1930.

Colmer T. D. (2003) Aerenchyma and an inducible barrier to radial oxygen loss facilitate root aeration in upland, paddy and deep-water rice (Oryza sativa L.). Annals of Botany 91:301-309.

Colmer T. D. and L. A. C. J. Voesenek (2009) Flooding tolerance: suites of plant traits in variable environments. Functional Plant Biology 36:665-681

Csurhes S. M., A. P. Mackey and L. Fitzsimmons (1999) Hymenachne (Hymenachne amplexicaulis) in Queensland. Pest Status Review Series, Land Protection. Department of Natural Resources and Mines. Queensland, Australia. $40 \mathrm{p}$.

Enríquez Q. J. F., A. Hernández G., A. R. Quero C. y D. Martínez M. (2015) Producción y manejo de gramíneas tropicales para pastoreo en zonas inundables. Folleto Técnico. SAGARPA - INIFAP - Colegio de Postgraduados. Texcoco, Edo. de México. 60 p.

Equiza M. A. and J. A. Tognetti (2002) Morphological plasticity of spring and winter wheats in response to changing temperatures. Functional Plant Biology 29:1427-1436.

Fabbri L. T., G. H. Rua and N. Bartoloni (2005) Different patterns of aerenchyma formation in two hygrophytic species of Paspalum (Poaceae) as response to flooding. Flora 200:354-360.

Gasser M. M., J. C. Ramos, J. C. Tivano y A. C. Vegetti (2002) Anatomía foliar de Bromus auleticus y Setaria lachnea sometidas a digestión in situ. Revista de la Facultad de Agronomía, La Plata 105:68-76.

Grimoldi A. A., P. Insausti, V. Vasellati and G. G. Striker (2005) Constitutive and plastic root traits and their role in differential tolerance to soil flooding among coexisting species of lowland grassland Internacional Journal of Plant Sciences 166:805-813.

Guevara O. L. I. y M. Ramia (2007) Anatomía foliar de Panicum L., sección Parvifolia (Poaceae, Paniceae) en Venezuela. Rodriguésia 58:73-83

Heinzen F., J. Ramos y J. C. Tivano (2002) Anatomía cuantitativa comparada de algunas especies de gramíneas de la provincia de Santa Fe. Revista FAVE-Ciencias Agrarias Ciencias Agrarias 1:57-63.

Medina E. and N. Motta (1990) Metabolism and distribution of grasses in tropical flooded savannas in Venezuela. Journal of Tropical Ecology 6:77-89.

Pérez C. V. y V. Cambi (2010) Anatomía vegetativa comparativa entre Chloridoideae (Poaceae) halófilas de importancia forrajera. Phyton 79:69-76.

Quero C. A. R., J. F. Enríquez Q. y L. Miranda J. (2007) Evaluación de especies forrajeras en América tropical, avances o status quo. Interciencia 32:566-571.

R Core Team (2016) R: A language and environment for statistical computing. R Foundation for Statistical Computing, Vienna, Austria URL https://www.R-project.org/. (Octubre 2016).

Ruzin S. E. (1999) Plant Microtechnique and Microscopy. Oxford University Press. New York. $336 p$

Striker G. G. (2012) Time is on our side: the importance of considering a recovery period when assessing flooding tolerance in plants. Ecological Research 27:983-987.

Van Soest P. J. (1993) Cell wall matrix interactions and degradation Session synopsis. In: Forage Cell Wall Structure and Digestibility. H. G. Jung, D. R. Buxton, R. D. Hatfield and J. Ralph (eds.). ASA, CSSA, SSSA. Madison, Wisconsin, USA. pp:377-395.

Vizcaíno V. I., J. A. Ruiz C., I. J. González A., J. Anguiano C. y S. Zepeda M. (2005) Recursos Edafo-Climáticos para la Planeación del Sector Productivo en el Estado de Colima. Libro Técnico Núm 2. Instituto Nacional de Investigaciones Forestales, Agrícolas y Pecuarias. Guadalajara, Jalisco. $172 \mathrm{p}$

Zheng W. J., G. C. Chen, C. L. Zhang, Y. X. Hu, L. H. Li, and J. X. Lin (2002) Physiological adaptation of habitat by ion distribution in the leaves of four ecotypes of reed (Phragmites australis). Acta Botanica Sinica 44:82-87. 